\title{
An in situ combustion process for recovering heavy oil using scaled physical model
}

\author{
Xian Zhang ${ }^{1} \cdot$ Qingwang Liu ${ }^{1} \oplus \cdot$ Zhenzhong Fan ${ }^{1} \cdot$ Qicheng Liu $^{2}$
}

Received: 12 September 2018 / Accepted: 19 April 2019 / Published online: 6 May 2019

(c) The Author(s) 2019

\begin{abstract}
In order to study the effects of formation thickness and structural dip on in situ combustion and the combustion performance in the $1 / 4$ of inverted nine-spot injection pattern, the scaled experimental system was developed based upon the ISC scaling law. The laboratory results show that within $1 / 4$ of inverted nine-spot injection pattern the main combustion zone was swept completely with the oil recovery of $75 \%$, leaving 5-15\% oil saturation in the cracking/vaporization zone. Gas override and early breakthrough became more and more serious when the formation thickness increased, and oil recovery in the reservoir with structural dip was much lower than that in the $0^{\circ}$ structural dip reservoir under same operating conditions. Conclusions have been drawn that employing nine inverted nine-spot injection pattern ISC can achieve a good oil recovery in G3-6-18 reservoir of Liaohe Oilfield in China. However, the formation thickness and the structural dip shall be taken into account when a project is designed as they play a major role on the sweeping efficiency. The sweeping efficiency can be enhanced by optimizing the operational parameters.
\end{abstract}

Keywords Heavy oil $\cdot$ In situ combustion $\cdot$ Thermal recovery $\cdot$ Scaled model $\cdot$ Laboratory

\section{Introduction}

In situ combustion (ISC) is a thermal recovery process with heat being generated in the reservoir by burning some of the original oil in place and then propagating the fire front under continuous air injection. The heat generated in situ increases the mobility of the unburned oil by decreasing the oil viscosity in the vicinity. ISC mechanisms are largely a function of oil composition and rock mineralogy (Sarathi 1999). The extent and nature of the chemical reactions between crude oil and injected air, as well as the heat generated in situ, depend on the oil matrix system. Laboratory studies, using crude and matrix from a prospective ISC project, are required prior to the design of any field operations (Ghafoor and Arvin 2010).

The one-dimensional combustion tube experiments are mandatory to determine the basic parameters needed to

Qingwang Liu

lqwprofessor@sohu.com

1 Petroleum Engineering Institute of Northeast Petroleum University, Daqing 163318, Heilongjiang, China

2 PetroChina Liaohe Oil Company, Panjin 124000, Liaoning, China design and implement field projects, such as the apparent atomic $H / C$ ratio, the volume of injected air and the volume of consumed fuel, etc. (Cheng 2012). These data are significant for mitigating the investment risks and making predictions of field test performance. However, it is beyond its ability to evaluate the effects of geological parameters, which have been proven to play a major role in the combustion process. The effects of geological parameters can only be studied using a scaled physical model (Greaves and Alhoni 2000).

Studies of ISC using scaled geometries are very limited, because of the extra complexity and cost. Nevertheless, the effort in this direction is worthwhile due to the valuable understanding to be gained from a physical scaled model of the process. Moreover, a scaled model can also be utilized to study and optimize well positioning and provide a more detailed picture of what is happening in the complex process of ISC (Garon et al. 1982).

In the past few decades, most of the scaled experiments mainly focused on injected gas override, the steady-state analysis of the combustion front, flame velocity and reaction rate, oil recovery, etc. Very limited scaled experimental studies of ISC were reported with regard to the effects of 
geological and operational parameters on the combustion (Coats 1980; Oklany 1992; Anis et al. 1983).

This paper mainly focuses on the influences of the well pattern, the structural dip and the formation thickness on the combustion front propagation and the sweeping efficiency using a scaled model, which had only been discussed theoretically in the previous studies, but not experimentally.

\section{Experimental}

\section{Scaled model setup}

Scaling laws shall be followed for scaled physical studies. The earliest scaling laws of a simplified ISC model was given in 1967, and a complicated scaling law taking into account geometry, gravity and dynamics was then developed for ISC (Caron et al. 1984). Liu et al. developed a more sophisticated scaling law taking the combustion reaction kinetics into consideration (Liu et al. 2013). This experimental system was developed based on Liu's scaling law.

The scaled combustion cells used for the experiments were rectangular boxes packed with oil sands from G3-6-18 reservoir of Liaohe Oilfield, and the thickness of cap rock (cement) and the layout of temperature measurement points (TMPs) was adjusted as required for different experimental objectives. Data acquisition system was set up to record temperature and pressure, analyze oil/gas sample composition pre/post ISC and monitor the combustion state during ISC. The experimental system is shown in Fig. 1.

\section{Experimental methods}

The experiments were designed to study the effects of formation thickness and structural dip on the combustion front propagation and the ISC performance within $1 / 4$ of inverted nine-spot injection pattern. The scaled model was in proportion to the actual target reservoir as per Liu's scaling law. The scaling factors between the model and prototype are given in Table 1. The viscosity index indicates temperature
Table 1 The scaling factors between the model and prototype

\begin{tabular}{llllll}
\hline Parameter & \multicolumn{2}{l}{ Prototype } & & \multicolumn{2}{l}{ Model } \\
\cline { 2 - 3 } \cline { 5 - 6 } \cline { 5 - 6 } & Unit & Value & & Unit & Value \\
\hline Well spacing & $\mathrm{m}$ & 105 & & $\mathrm{~cm}$ & 50 \\
Porosity & $\%$ & 21.2 & & $\%$ & 30.0 \\
Effective permeability & $\mathrm{D}$ & 1.376 & & $\mathrm{D}$ & 2.0 \\
Oil saturation & $\%$ & 60.0 & & $\%$ & 60.0 \\
Air injection rate & $\mathrm{m}^{3} / \mathrm{d}$ & 10,000 & & $\mathrm{~L} / \mathrm{min}$ & 10 \\
Thermal diffusivity & $\mathrm{m}^{2} / \mathrm{s}$ & $9.62 \times 10^{-7}$ & & $\mathrm{~m}^{2} / \mathrm{s}$ & $4.49 \times 10^{-7}$ \\
Viscosity index & & 3.77 & & & 2.28 \\
Pressure & $\mathrm{MPa}$ & $3-4$ & & $\mathrm{MPa}$ & 3 \\
Structural dip & $\circ$ & 15 & & \\
Formation thickness & $\mathrm{m}$ & 20 & $\mathrm{~cm}$ & 9.5 \\
& & 40 & & 19.0 \\
& & 60 & & 28.6 \\
\hline
\end{tabular}

dependence of kinematic viscosity. It was calculated according to procedure A of ASTM D2270. The calculated viscosity index in the prototype is very close to that in the model, and the minor difference might be caused by the experimental error during measurements and calculation. The formation thickness in the model is designed as $9.5 / 19.0 / 28.6 \mathrm{~cm}$ to represent the actual thickness $20 / 40 / 60 \mathrm{~m}$ according to the geometrical similarity of model.

Case \#1 combustion cell was packed with sands and dehydrated crude oil obtained from G3-6-18 reservoir demonstrate the $1 / 4$ of inverted nine-spot injection pattern. The model dimension is $50 \mathrm{~cm} \times 50 \mathrm{~cm} \times 4 \mathrm{~cm}$; as shown in Fig. 2, one air injector and three oil producers are located in the model to simulate the $1 / 4$ of inverted nine-spot injection pattern which is the most common well pattern within Liaohe Oilfield. Two pressure measurement points (PMPs) and one hundred and thirty-nine thermocouples (TMP) were located in the model for monitoring pressure and temperature during ISC.

Prior to activating the ignitor, air was injected at low rate into the model to ensure the connectivity. The power of ignitor was incrementally increased to make the various
Fig. 1 The scaled physical experimental system of ISC

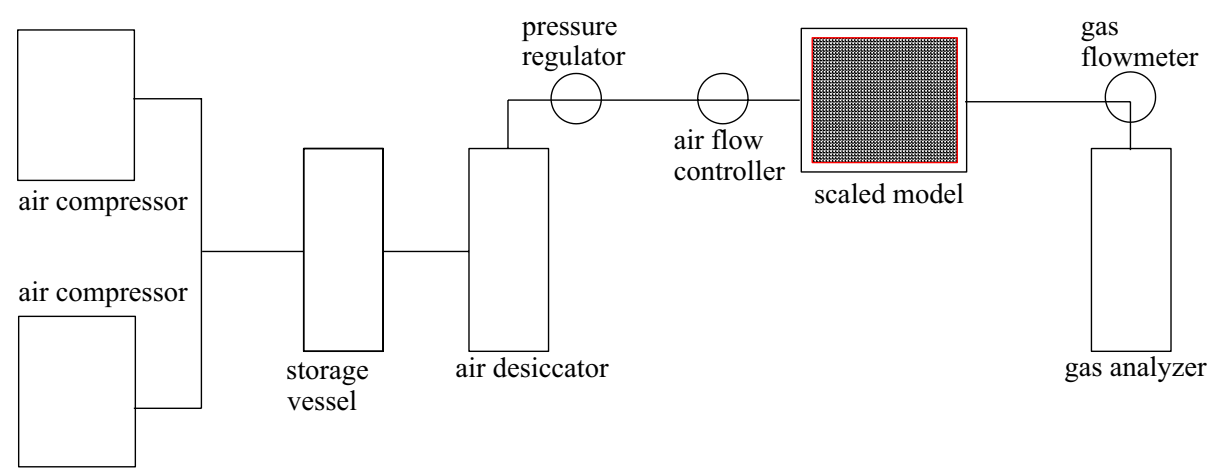




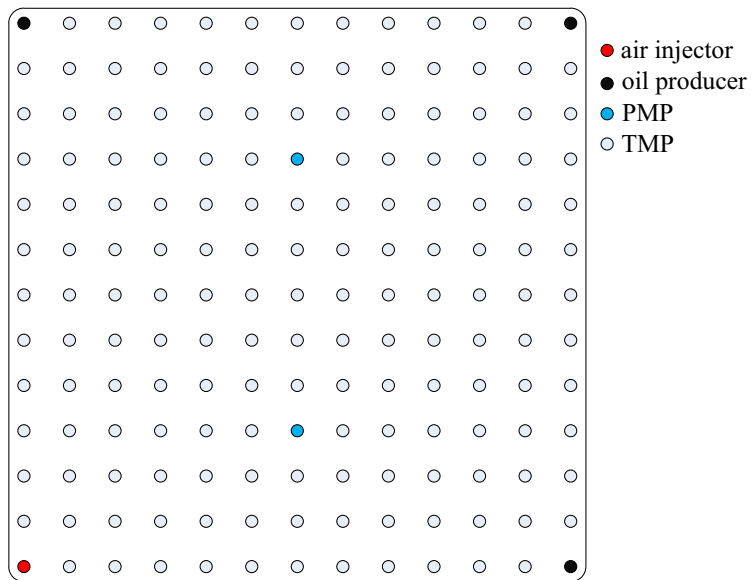

Fig. 2 The layout of injector, producer, PMPs and TMPs in the model

compositions of heavy oil crack or evaporate at different temperatures, leaving sufficient fuels for the oxidation. The accurate temperatures were obtained at 139 TMPs, and temperature distribution during combustion process was analyzed through interpolation method.

Case \#2 was to study the effects of pay zone thickness on the ISC performance due to the fact that Liaohe G3-6-18 reservoir is thick-bedded and massive (maximum $103.8 \mathrm{~m}$ ). $20 \mathrm{~m}, 40 \mathrm{~m}$ and $60 \mathrm{~m}$ pay zones were scaled in the scaled model, with experimental parameters shown in Table 2. The oil producers could be adjusted to simulate various operational scenarios based upon the combustion front propagation.

Case \#3 was designed to study the effects of structural dip on the ISC performance. The combustion cell was packed to simulate 40 -m-thick reservoir with structural dip of $15^{\circ}$; as is shown in Fig. 3, there were 65 TMPs set up to collect temperature data and the producer was located downdip. The well spacing between injector and producer is $50 \mathrm{~cm}$.

\section{Results and discussion}

The temperature data were collected from TMPs, and the temperature profiles were plotted using interpolation and inversion method. Considering the potential impacts caused by excessive sensors on porous medium, we did not place

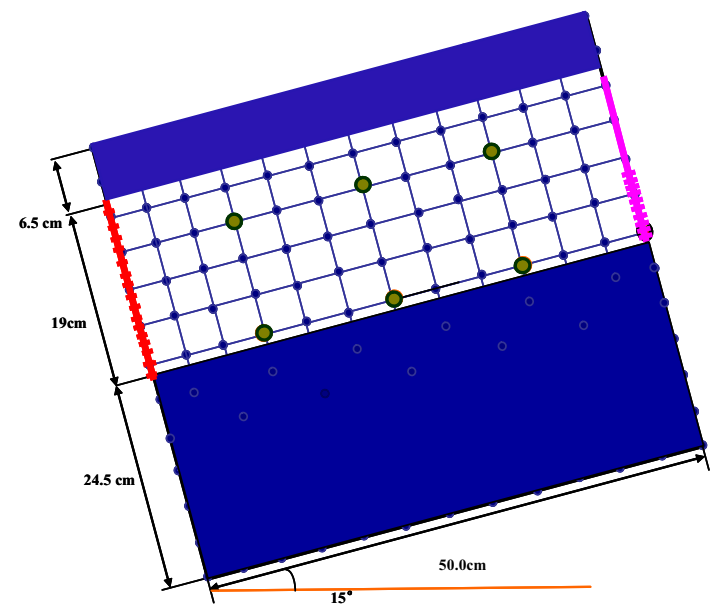

Fig. 3 The model of 40-m-thick reservoir with structural dip of $15^{\circ}$

sufficient pressure sensors in the model to determine the pressure contours. The production pressure drop was maintained between 1.1 and $1.3 \mathrm{MPa}$, and the production in all cases was stable under such circumstances. The $\mathrm{CO} / \mathrm{CO}_{2} /$ $\mathrm{O}_{2}$ contents in the effluent gases were analyzed to assist in determining the ISC performance and fire breakthrough. If required the optimization would be applied by adjusting the producers. The $\mathrm{CO} / \mathrm{CO}_{2} / \mathrm{O}_{2}$ contents under stabilized conditions in different cases were $4.0 \pm 0.5 \%, 10.1 \pm 0.4 \%$ and $3.2 \pm 0.4 \%$, respectively. The details of different cases are discussed as follows.

\section{Case \#1}

Figure 4 shows the combustion front propagation in the model over a period of ISC. The oil around the ignitor was ignited first and the peak temperature reached $700{ }^{\circ} \mathrm{C}$ but to last only $6 \mathrm{~min}$, and then dropped to $400{ }^{\circ} \mathrm{C}$ approximately. The temperature was observed more than $500{ }^{\circ} \mathrm{C}$ in the center of the cell with the combustion front propagation and the heat expanded to the production well gradually.

In the process of the experiment, the significant observations were that the combustion front advanced to the production wells in relation to the air flow, and the flame could sweep any part in the model where the air flew through. The direction of the combustion front propagation was more

Table 2 Experimental parameters with different reservoir thickness

\begin{tabular}{|c|c|c|c|c|c|c|}
\hline Case & $\begin{array}{l}\text { Reservoir thick- } \\
\text { ness, } m\end{array}$ & Packed with & Oil saturation, $\%$ & Cell dimension, $\mathrm{cm}$ & TMPs & PMPs \\
\hline$\# 1$ & 20 & Dehydrated crude oil and quartz sands & 60 & $50 \times 9.5 \times 4$ & 39 & 3 \\
\hline$\# 2$ & 40 & & & $50 \times 19 \times 4$ & 65 & 6 \\
\hline \#3 & 60 & & & $50 \times 28.6 \times 4$ & 91 & 5 \\
\hline
\end{tabular}



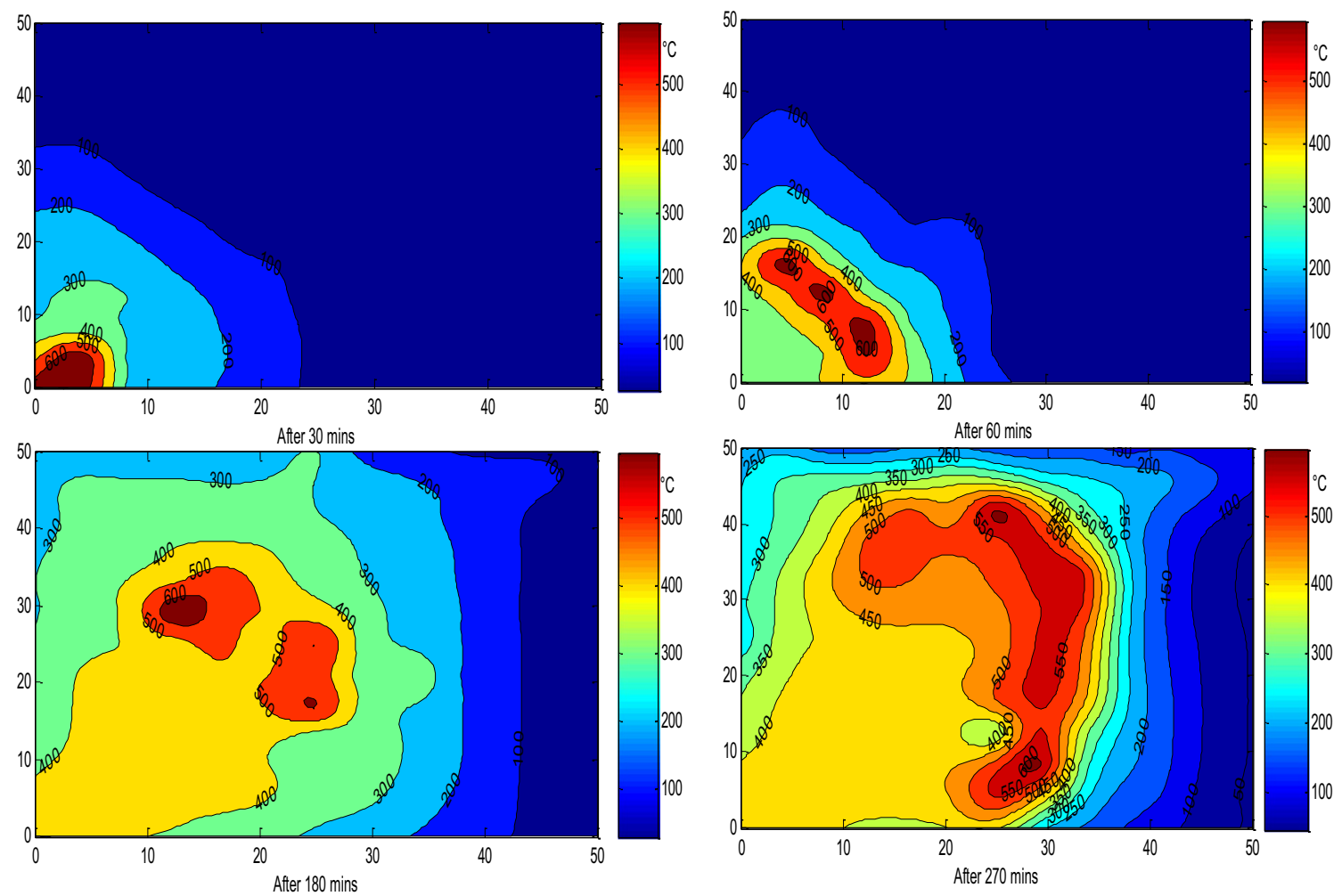

Fig. 4 The combustion front propagation in the model

likely toward nearby wells rather than the diagonal well due to the larger distance. The combustion front propagation could be controlled in order for the better sweep efficiency by optimizing the operational parameters.

Figure 5 shows that the oil sands in the main combustion zone became gray, loose and almost oil free. This indicated the sands being swept completely. In the high-temperature zones, the oil that did not burn formed condensed coke-like materials on the rock.

As is known, in the cracking/vaporization zone the crude is modified by the high temperature of the combustion process. The light ends vaporize and are transported
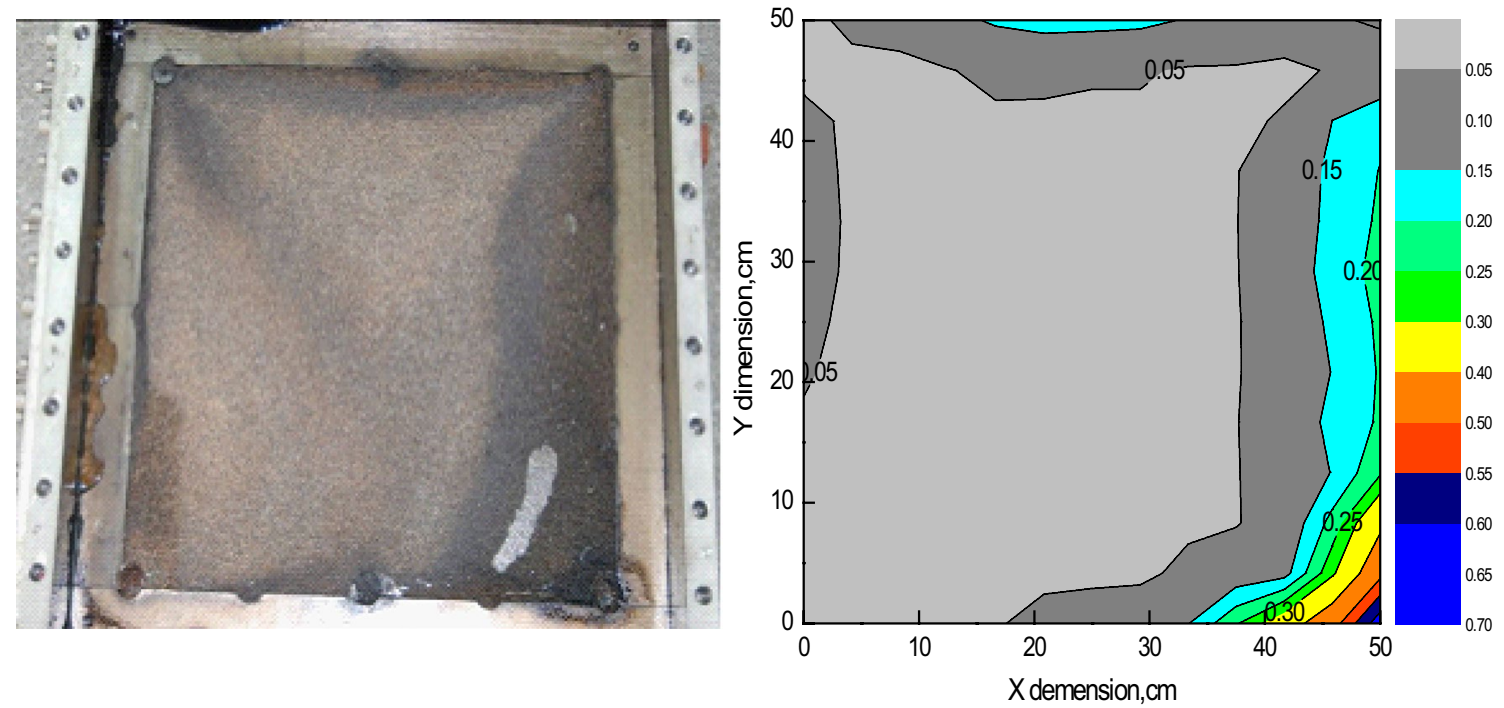

Fig. 5 Photograph of post ISC and the saturation distribution 
downstream where they condense and mix with the original crude. The heavy ends pyrolize, producing $\mathrm{CO}_{2}, \mathrm{CO}$, hydrocarbon gases and solid organic fuel deposited on the rock. The deposited oil sands were scanned through scanning electron microscopy; as is shown in Fig. 6, the coke-like materials deposited on the sands and filled the porosity resulting in reduction of permeability, which is the main reason for the sharp increase in injection pressure during a field project. These deposited oil sands contained 5-15\% oil after combustion. The calculated oil recovery of the ISC is $75 \%$.

\section{Case \#2}

Figure 7 shows the combustion front propagation in the models for $20 \mathrm{~m}$ pay zones (from top to bottom). The temperature change indicates the combustion front propagation. The well at the right side is the injection well, and the one at the left side is the production well. In all figures of temperature profile, the red dot lines represent the perforation in injectors and the black dot lines represent the perforation in producers.

In the experiment of $20 \mathrm{~m}$ scaled pay zone, the flame was formed at the bottom of the well at the very beginning and advanced to the production well. The tongue fingering phenomenon was observed while the combustion front moved forward to the production well, and gases broke through into the production well when the combustion front approached. The peak temperature was $634{ }^{\circ} \mathrm{C}$, and the average was $500{ }^{\circ} \mathrm{C}$ in the combustion process. The oil recovery was $64.7 \%$.

Figure 8 shows the combustion front propagation in the models for $40 \mathrm{~m}$ pay zones. In the experiment of $40 \mathrm{~m}$ scaled pay zone, the flame was formed above the perforated intervals of the injection well and moved with the air flow. Gas override was observed, and the movement of the combustion

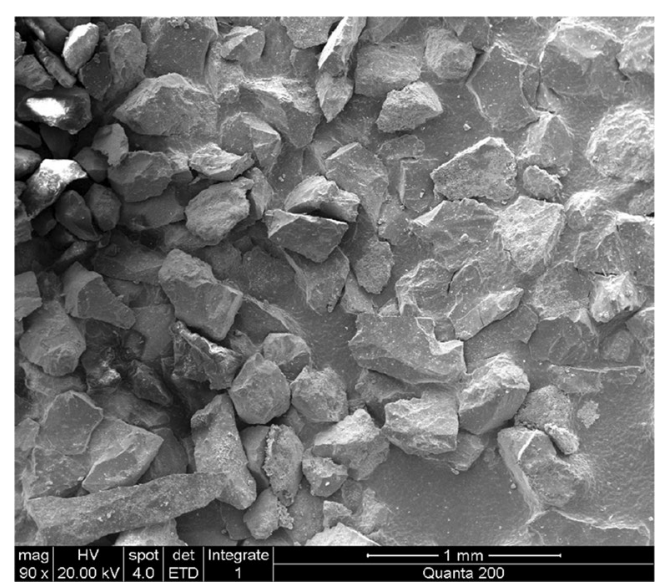

Fig. 6 The results of scanning electron microscopy on deposited oil sands

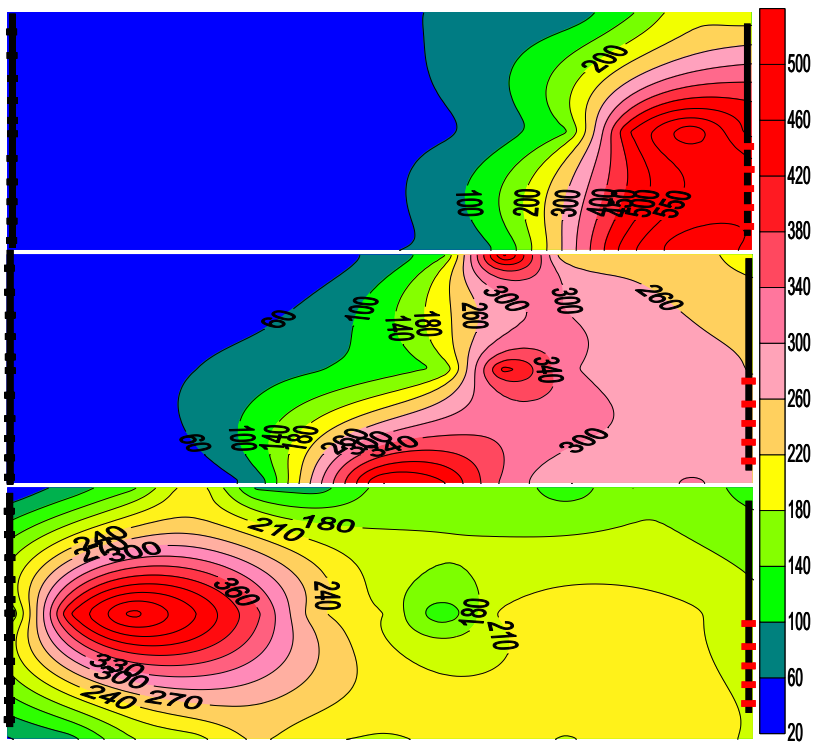

Fig. 7 The combustion front propagation in the model for $20 \mathrm{~m}$ pay zones

front became more irregular. When the combustion front approached to the bottom of the production well, gases broke through resulting in a sharp temperature increase in the combustion zone. The oil recovery was $61.7 \%$.

Figure 9 shows the combustion front propagation in the models for $60 \mathrm{~m}$ pay zones. In the experiment of $60 \mathrm{~m}$ scaled pay zone, the gas override and the irregular combustion front movement became more serious. The combustion front advanced along the top of the reservoir and eventually broke through into the production well with the airflow, leaving a large unswept region at the bottom of the reservoir. The oil recovery was only $21.4 \%$.

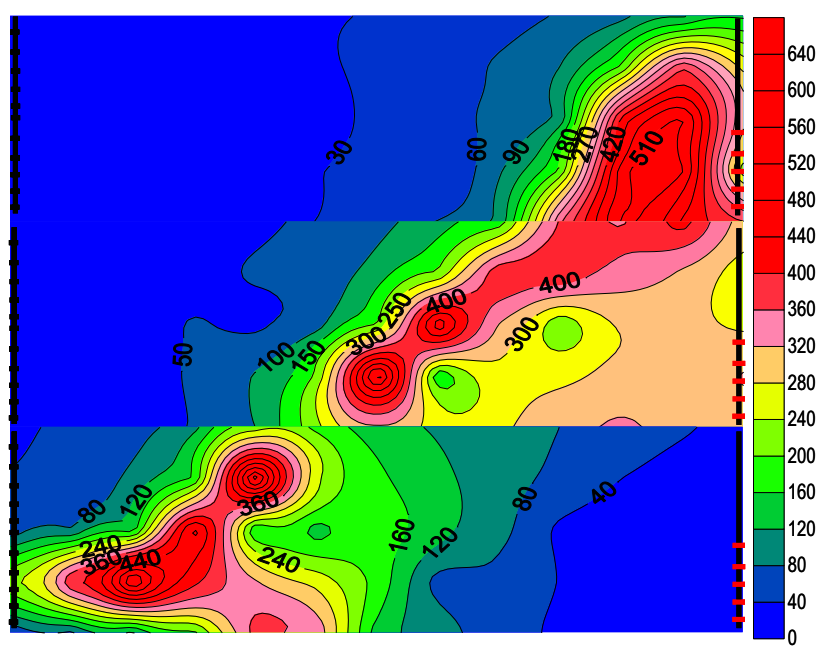

Fig. 8 The combustion front propagation in the model for $40 \mathrm{~m}$ pay zones 

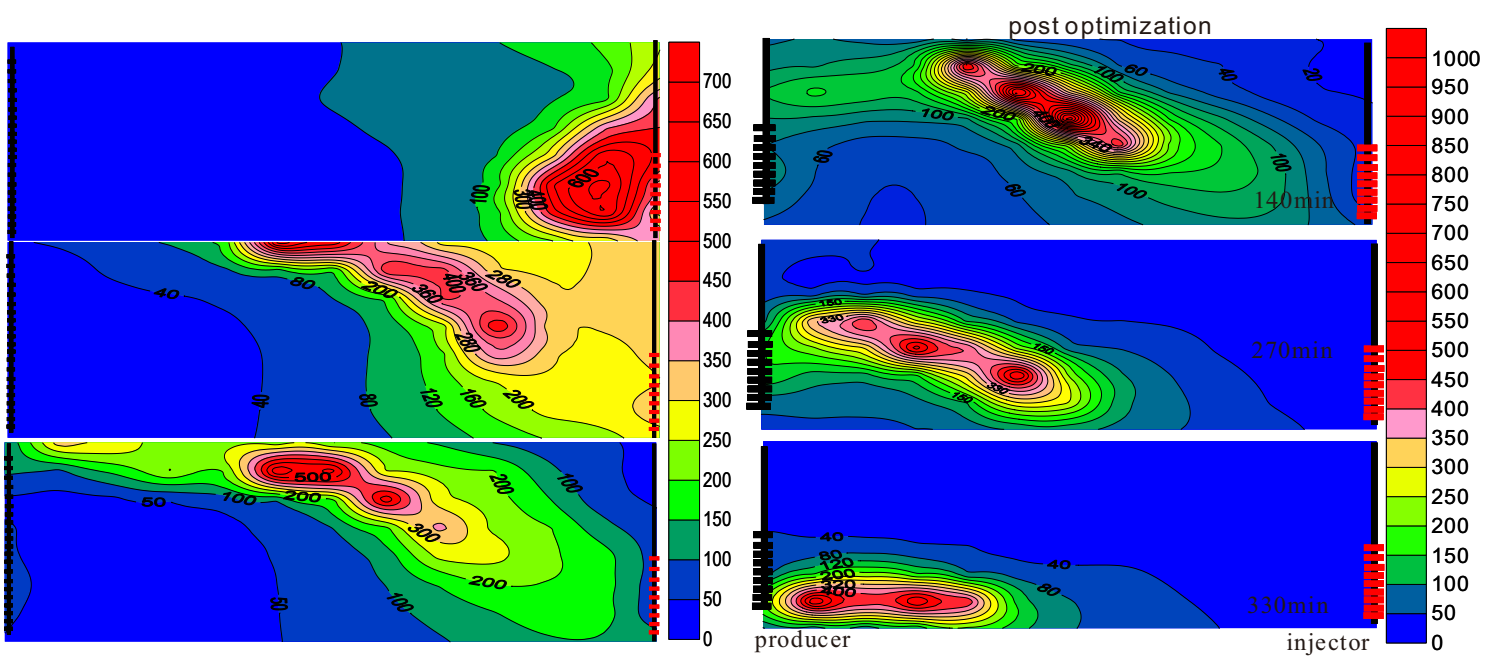

Fig. 9 The combustion front propagation in the model for $60 \mathrm{~m}$ pay zones

As is known, the large difference in density between air and the reservoir fluids gives the air a tendency to override the oil column and consequently bypass much of the oil if the reservoir exceeds a critical thickness. A thin oil sand, $20 \mathrm{~m}$ thickness in the experiment, tends to counter this override tendency and favor a more uniform displacement and vertical sweep. In comparison, rapid transfer of heat to the bottom of the sand in a thin reservoir will permit combustion front to advance at the bottom more rapidly than it would be possible in a thick reservoir. The gas override and early breakthrough exert a major impact in a thick reservoir on sweeping efficiency resulting in a reduction in oil recovery.

In order to minimize the gas override and early breakthrough, it is necessary to optimize the operational parameters. A few production wells were placed with various perforated intervals for selective zone production at the breakthroughs. The middle and the bottom of Fig. 9 shows the combustion front movement after the optimization. As the perforated intervals were adjusted, the combustion front movement could be controlled and eventually sweep the bottom section of the reservoir, which led to a higher sweep efficiency. It is applicable to control the combustion by optimizing the operational parameters to minimize the gas override and early breakthrough.

Figure 10 shows the oil recovery comparison pre- and post-optimization in $20-\mathrm{m}, 40-\mathrm{m}$ and $60-\mathrm{m}$ reservoirs. The oil recovery was $64.7 \%, 61.7 \%$ and $21.4 \%$, respectively, which demonstrated that less oil could be driven due to gas override and early breakthrough. However, the oil recovery increased by $10.1 \%$ and $38.6 \%$ in $40-\mathrm{m}$ and $60-\mathrm{m}$ reservoir after the optimization for selective zone production. In 20-m reservoir, the operational parameter did not impact the oil recovery.

\section{Case \#3}

Figure 11 shows the comparison of the combustion front propagation in $40-\mathrm{m}$ reservoir of different structural dip $\left(0^{\circ}\right.$ and $15^{\circ}$ ). The distance that the combustion front travelled from injector to producer became relatively short due to the structural dip. The combustion front experienced an early breakthrough, and the gas override was more serious than in the reservoir with $0^{\circ}$ structural dip, which resulted in the poor sweeping efficiency.

Figure 12 shows the oil recovery comparison of ISC in $40-\mathrm{m}$ reservoir of different structural dip $\left(0^{\circ}\right.$ and $\left.15^{\circ}\right)$. The oil recovery of ISC in 40-m reservoir with $15^{\circ}$ structural dip was $42.3 \%$, much lower than the $71.8 \%$ in the $0^{\circ}$ structural dip reservoir under same operating conditions. The breakthrough occurred at a relatively early stage resulting in an inefficient sweeping. It demonstrates that structural dip and the resulting gravity dominance played a significant role in the ISC process, especially when the production well is located downdip.

Theoretically the injected air and combustion front movement will be more rapid toward up dip wells. In dipping reservoir, it is advisable to locate the air injectors downdip and production wells up the structure to compensate for the expected flow of air up dip.

\section{Conclusion}

The scaled experimental system was developed based upon the ISC scaling law. Three experiments were conducted to study ISC performance in $1 / 4$ of inverted nine-spot injection pattern (Case \#1), the effects of formation thickness (Case \#2: $20 \mathrm{~m}, 40 \mathrm{~m}, 60 \mathrm{~m}$ ) and structural dip (Case \#3: 
Fig. 10 The oil recovery comparison pre- and postoptimization in 20-m, 40-m and 60-m reservoirs
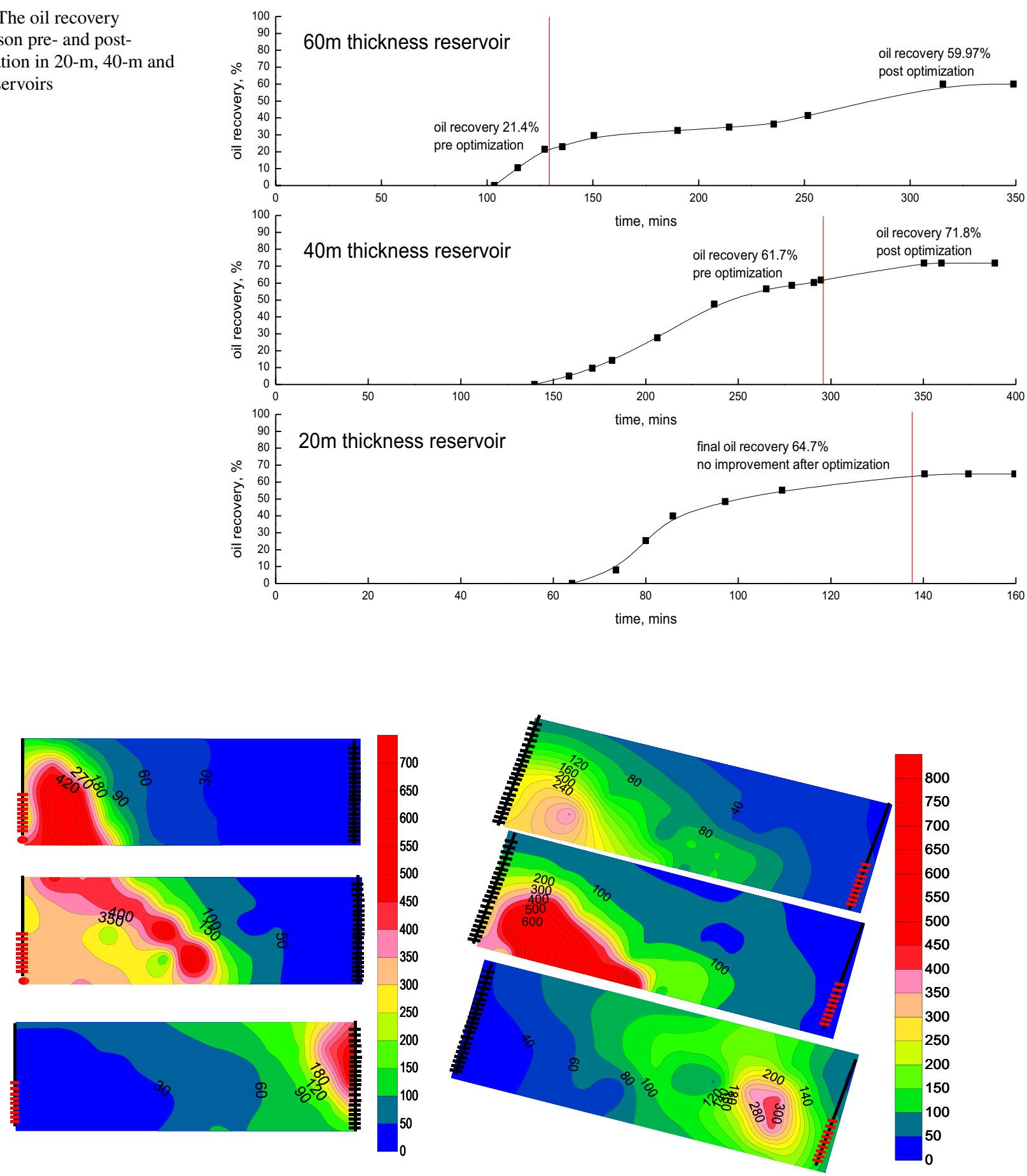

Fig. 11 The combustion front propagation in 40-m reservoir of different structural dip $\left(0^{\circ}\right.$ and $\left.15^{\circ}\right)$

$0^{\circ}, 15^{\circ}$ ) on combustion front propagation and performance in Liaohe heavy oil reservoir.

The laboratory results of Case \#1 show that the direction of the combustion front propagation was more likely toward nearby wells rather than the diagonal well. The main combustion zone was swept completely with the oil recovery of $75 \%$, leaving $5-15 \%$ oil saturation in the cracking/vaporization zone.

The laboratory results of Case \#2 show that gas override and early breakthrough became more and more serious when the formation thickness increased. Compared with $64.7 \%$ and $61.7 \%$ oil recovery in $20-\mathrm{m}$ and $40-\mathrm{m}$ reservoir, it could 


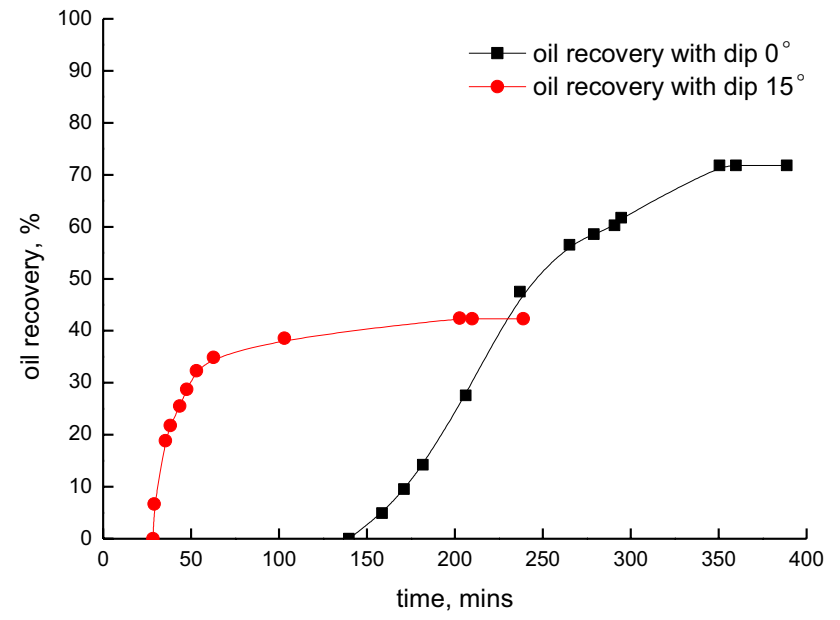

Fig. 12 The oil recovery comparison of ISC in 40-m-thick reservoir of different structural dip $\left(0^{\circ}\right.$ and $\left.15^{\circ}\right)$

only achieve $21.4 \%$ in $60-\mathrm{m}$ reservoir. But it could be elevated to $59.97 \%$ by optimizing the operational parameters.

The laboratory results of Case \#3 show that the oil recovery of ISC in $40-\mathrm{m}$ reservoir with $15^{\circ}$ structural dip was $42.3 \%$, much lower than the $71.8 \%$ in the $0^{\circ}$ structural dip reservoir under same operating conditions.

It is concluded that when employing nine inverted ninespot injection pattern ISC can achieve a good oil recovery in G3-6-18 reservoir of Liaohe Oilfield in China. However, the formation thickness and the structural dip shall be taken into account when a project is designed as they play a major role on the sweeping efficiency. The proper adjustment of operating parameters could control the fire breakthrough and effectively enhance the oil recovery.

Acknowledgements The authors thank PetroChina Innovation Fund (Grant Number 2018D-5007-0212), National Science and Technology Major Project (Grant Number 2016ZX05002006) and for financial support to this research. The Northeast Petroleum University Scientific Research Start-up Support is also appreciated.

\section{Compliance with ethical standards}

Conflict of interest The authors confirm that this article content has no conflict of interest.

Open Access This article is distributed under the terms of the Creative Commons Attribution 4.0 International License (http://creativeco mmons.org/licenses/by/4.0/), which permits unrestricted use, distribution, and reproduction in any medium, provided you give appropriate credit to the original author(s) and the source, provide a link to the Creative Commons license, and indicate if changes were made.

\section{References}

Anis M, Hwang MK, Odeh AS (1983) A sensitivity study on the effect of parameters on results from an in situ combustion simulator. Soc Pet Eng J 23:259-264

Caron AM, Kumar M, Lau KK, Sherman MD (1984) A laboratory investigation of sweep during oxygen and air fireflooding. SPE Reserv Eng 1:565-574

Cheng HQ (2012) Physical simulation research on basic parameters of in situ combustion for super heavy oil reservoirs. Spec Oil Gas Reserv 19:107-110

Coats KH (1980) In-situ combustion model. Soc Pet Eng J 20:533-554

Garon AM, Geisbrecht RA, Lowry WE (1982) Scaled model experiment of fireflooding in tar sands. J Pet Technol 34:2158-2166

Ghafoor K, Arvin KS (2010) In situ combustion process, one of IOR methods livening the reservoirs. Pet Coal 52:139-147

Greaves M, Al-honi M (2000) Three-dimensional studies of in situ combustion-horizontal wells process with reservoir heterogeneities. J Can Pet Technol 39:25-33

Liu QC, Cheng HQ, Zhang Y, Zhao QH, Liu BL (2013) Research on similarity criteria of in situ combustion process. Spec Oil Gas Reserv 01:111-116

Oklany SFAJ (1992) An in situ combustion simulator for enhanced oil recovery. Thesis, University of Salford

Sarathi P (1999) In-situ combustion handbook principles and practices. National Petroleum Technology Office, Tulsa, OK

Publisher's Note Springer Nature remains neutral with regard to jurisdictional claims in published maps and institutional affiliations. 